\title{
IMPACTS OF INOCULATION WITH Sinorhizobium meliloti STRAINS DIFFERING IN SALT TOLERANCE ON THE PRODUCTIVITY AND HABITUS OF ALFALFA (Medicago sativa L.)
}

\section{N.A. PROVOROV, O.P. ONISHCHUK, O.N. KURCHAK}

\author{
All-Russian Research Institute for Agricultural Microbiology, Federal Agency of Scientific Organizations, 3, sh. \\ Podbel'skogo, St. Petersburg, 196608 Russia, e-mail provorov@newmail.ru \\ Acknowledgements: \\ The authors are grateful to L.A. Lutova for critical comments on the article and to S.N. Yurhel for mutant GL1. \\ Supported by Russian Science Foundation grant № 14-26-00094 \\ Received December 30, 2015
}

\section{Abstract}

Symbiotic efficiency (SE) in nodule bacteria (rhizobia) characterizers their adaptive potential and practical significance. This trait is closely related to fixation of molecular nitrogen $\left(\mathrm{N}_{2}\right)$ which is implemented by rhizobia in root nodules and is controlled by genotypes of both partners. The highest intensity of $\mathrm{N}_{2}$ fixation is typical for fast-growing rhizobia (Rhizobium, Sinorhizobium). However, SE (impact of the rhizobia inoculation on the plant biomass) is determined by many gene systems of rhizobia including those not related to operation of nitrogenase. Therefore, $\mathrm{N}_{2}$-fixing activity and SE should be considered as two different symbiotic features. Specifically, rhizobia can synthesize biologically active substances (phytohormones, vitamins, lumichrome) which influence the development of host plants. The aim of our research was to explore the impacts of Sinorhizobium meliloti strains which are fixing actively $\mathrm{N}_{2}$ but are contrasting in salt resistance on productivity and on the indices of habitus (ratios of different plant morphometric traits) in perennial tetraploid alfalfa (Medicago sativa). These impacts were studied under influences of the salinity stress and of the microsymbiont mutations affecting SE. We used S. meliloti strains: 1021 (standard laboratory strain), CXM1-188 (UV-induced mutant of strain CXM1 possessing an increased SE) and CA67 (strain isolated from the Tajikistan soils). Besides, we used Tn5-induced mutants with a decreased SE: F (obtained from strain CA67 in this research) and GL1 (obtained from strain 1021 at Dalhouse University, Canada). Seeds of alfalfa cultivar Agnia resistant to edaphic stresses were obtained from AllRussia Research Institute of Fodders named after V.R. Williams (Lobnya, Moscow Province). The legume-rhizobia symbiosis was studied in the microvegetative trials by analyzing different morphometric traits (mass and length of shoots and roots) and their ratios as dependent on the salinity stress $(0.6 \% \mathrm{NaCl})$. In the absence of stress, all $S$. meliloti strains possessing the high $\mathrm{N}_{2}$-fixing activities but contrasting in salt tolerance resulted in the increased mass and length of alfalfa shoots combined with the decreased length of roots. These effects lead to a drastic change in the plant habitus (shoot:root ratios for length increased 2-3 fold) which are perhaps responsible for the high intensity of symbiotrophic alfalfa development. Under the salinity stress, no significant changes of the shoot:root length ratio were revealed, while the mass:length ratio in shoots was increased from 0.16 $0.34 \mathrm{mg} / \mathrm{mm}$ to $0.52-0.68 \mathrm{mg} / \mathrm{mm}$. In plants inoculated with the salt-sensitive $S$. meliloti strain CA67 (unable to grow in the presence of $3 \% \mathrm{NaCl}$ ), loss of $\mathrm{SE}$ induced by the salinity stress was accompanied by the increase of shoot and root length (by $36 \%$ and $79 \%$, respectively) although their masses were not changed with respect to non-inoculated control. In plants inoculated with the salttolerant strains CXM1-188 and 1021, SE under the salinity stress was retained while the stimulatory impacts on the shoot and root growth were not revealed. The Tn5 mutants F and GL1 characterized by the decreased SE did not differ from parental strains in their influences on plant habitus. In this work we demonstrated for the first time that the SE depends on two factors - nutritional (determined by $\mathrm{N}_{2}$ fixation) and regulatory (possibly mediated by modulations of hormonal status in plants which influence the activities of shoot and root meristems). The genetic modifications of regulatory (growth-stimulatory) rhizobia activities may represent an important approach for optimizing the symbiotrophic nitrogen nutrition in the leguminous crops and for their adaptations to the edaphic (osmotic) stresses.

Keywords: nodule bacteria (rhizobia), leguminous plants, $\mathrm{N}_{2}$ fixation, growth-stimulatory activity, symbiotic efficiency, salinity stress, plant habitus, Medicago sativa, Sinorhizobium meliloti

Symbiotic efficiency (SE), or the ability to increase productivity (weight, 
nitrogen accumulation, seed number) in legume host plants is the most important trait of nodule bacteria (rhizobia) that characterizes their adaptive capacity and practical importance $[1,2]$. This trait is closely related to molecular nitrogen $\left(\mathrm{N}_{2}\right)$ fixation which is implemented by rhizobia in root nodules and is controlled by the genotypes of both partners [3]. However, the genetic mechanisms of SE control are still poorly understood.

The highest $\mathrm{N}_{2}$ fixation is typical of fast-growing rhizobia (Rhizobium, Sinorhizobium) that are capable of transformation into a non-viable intracellular bacteroides at symbiosis. Their high $\mathrm{N}_{2}$-fixing activity is due to the irreversible inhibition of cellular functions required for autonomous existence, including different phases of nitrogen-carbon metabolism and cellular structure biogenesis [4].

$\mathrm{SE}$ is known to be determined by numerous rhizobian gene systems including those not related to functioning nitrogenase (enzyme catalyzing $\mathrm{N}_{2}$ recovery into $\mathrm{NH}_{3}$ ), therefore, $\mathrm{N}_{2}$-fixing activity and SE should be considered as two different symbiotic features [2]. Thus, the analysis of alfalfa rhizobia (Sinorhizobium meliloti) Tn5-induced mutants with increased SE [5] identified a series of negative symbiosis regulators (eff genes), neither of which is part of nif and fix operons encoding nitrogenase structure, activation of its synthesis, and energy supply [6]. Functional relationship with $\mathrm{N}_{2}$-fixing has been found for several eff genes only, for example $p h b A$ the inactivation of which violates the synthesis of poly- $\beta$-hydroxybutyrate (acetoacetyl-CoA) precursor and increases the amount of carbon directed by bacterial cells for nitrogenase energy supply [7].

Rhizobia can synthesize a variety of biologically active substances which have effects on the development of host plants: phytohormones [8-10], vitamins [11-12], and lumichrome [14-15]. Lipo-chitooligosaccharide Nod factors by which rhizobia activate nodule development, alter the synthesis of phytohormones in plants dramatically, increasing the cytokinin/auxins ratio in the roots, resulting in activated division of cortex and pericycle cells which leads to nodule primordia initiation [16]. Changes in the hormonal status of legumes caused by rhizobia can alter the ratio of the key morphometric parameters of aerial and underground organs (plant habitus) associated with SE [17].

Previously, we found the length of annual diploid alfalfa (Medicago truncatula) shoots to reduce sharply (by 3-14 times) under the effect of salinity stress while maintaining their weight [18]. In some M. truncatula lines, habitus is normalized when inoculated with $\mathrm{N}_{2}$-fixing Sinorhizobium meliloti, which confirms the similarity of symbiosis mechanisms and plant response to salinity stress. It is reasonable to assume that the regulatory impact of microsymbionts on the plants would be most pronounced under the effect of genotype and environmental factors that reduce the intensity of $\mathrm{N}_{2}$ fixation.

In this study, we demonstrated for the first time that manifestation of rhizobia SE depends on the factors of two types - nutritional (determined by the intensity of $\mathrm{N}_{2}$ fixation) and regulatory ones (possibly associated with modulations of plant hormonal status which affects root and shoot meristem activity).

The objective of our research was to study the impacts of Sinorhizobium meliloti strains that fix $\mathrm{N}_{2}$ actively but are contrasting in salinity tolerance on the productivity and habitus in perennial tetraploid alfalfa (Medicago sativa L.) under salinity stress and when microsymbiont mutants affected in SE used.

Technique. We used alfalfa nodule bacteria strains capable of active $\mathrm{N}_{2}$ fixation: 1021 (a standard laboratory strain) [19], SHM1-188 (UV-induced mutant of strain SHM1 possessing an increased SE) [20], and CA67 (strain isolated from the Tajikistan soils) [21]. Besides, we studied Tn5-induced mutants F (obtained from strain CA67 in this research) and GL1 (obtained from strain 1021 at Dalhousie 
University, Canada). Salinity tolerance of strains was determined on solid (1.5\% agar) TY medium with various $\mathrm{NaCl}$ concentrations (2.0 to $4.5 \%)$.

Seeds of alfalfa cultivar Agnia resistant to edaphic stresses were obtained from V.R. Williams All-Russia Fodder Research Institute (Lobnya, Moscow Province).

The legume-rhizobia symbiosis was studied in microvegetative trials in the plants grown in sterile test tubes on agarized $(0.7 \%)$ nitrogen-free Krasil'nikov-Korenyako medium in 8-10-fold replicates for 30 days [20]. Dry weight gain in the shoots of plants inoculated with rhizobia versus control (not inoculated) was a SE indicator.

To analyze the effects of salinity stress on alfalfa morphometric parameters (shoot length, root length, dry weight of roots), the plants were grown in the medium containing $0.6 \% \mathrm{NaCl}$.

Statistical data processing was performed by analysis of variance [22] using Microsoft Office Excel 2007 software.

Results. The strains used in the study were contrasting in their tolerance to salinity stress: 1021 and SHM1-188 were able to grow on solid agarized medium 79 supplemented with $3 \% \mathrm{NaCl}$ ( $\mathrm{R}$ phenotype), whereas the growth of strain CA67 was inhibited on this medium (S phenotype). Tn5-induced mutants demonstrated reduced SE $\left(\right.$ Eff $^{+/-}$phenotype), where strain CA67 mutant $\mathrm{F}$ also had increased salinity tolerance and was able to grow in the presence of $3.5 \% \mathrm{NaCl}$.

In symbiosis with alfalfa in the absence of salinity stress, $\mathrm{S}$ strain CA67 demonstrated the highest SE: shoot weight and length in inoculated plants increased by 163 and $169 \%$, respectively, versus control, whereas the root length decreased insignificantly (7 \%) (Table 1).

1. Relative changes $(\%)$ in morphometric parameters in alfalfa Medicago sativa $\mathrm{L}$. inoculated with rhizobia Sinorhizobium meliloti strains different in their salinity tolerance (microvegetative trial)

\begin{tabular}{l|c|c|c|c|c|c}
\hline \multirow{2}{*}{ Strain } & \multicolumn{3}{c|}{ No salinity stress } & \multicolumn{3}{c}{ Under salinity stress $(0.6 \% \mathrm{NaCl})$} \\
\cline { 2 - 7 } & $\mathrm{SW}$ & $\mathrm{SL}$ & $\mathrm{RL}$ & $\mathrm{SW}$ & $\mathrm{SL}$ & $\mathrm{RL}$ \\
\hline CA67 (S) & $+163^{*}$ & $+169^{*}$ & -7 & +5 & $+36^{*}$ & $+79^{*}$ \\
1021 (R) & $+73^{*}$ & $+90^{*}$ & $-28^{*}$ & $+138^{*}$ & -1 & -7 \\
CXM1-188 (R) & $+96^{*}$ & $+56^{*}$ & $-21^{*}$ & $+160^{*}$ & $-24^{*}$ & -6
\end{tabular}

$\mathrm{N}$ o t e. Strain capability of growing on $3 \% \mathrm{NaCl}$ containing medium is specified in brackets: $\mathrm{R}-$ presence of growth, S - absence of growth. SW - dry weight of shoots, SL - shoot length, RL - root length.

${ }^{*} \mathrm{P}_{0}<0.05$ (significant difference with not inoculated control).

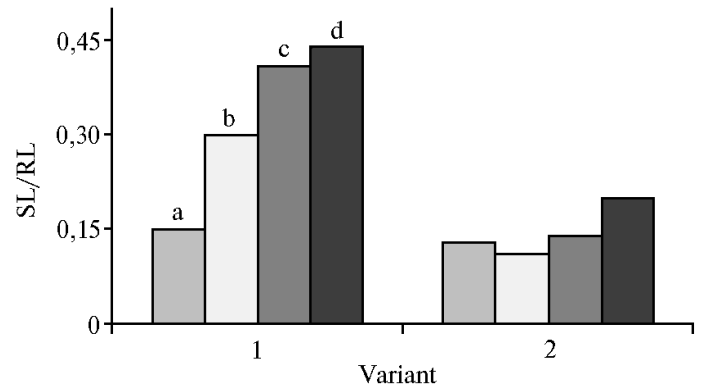

Root length/shoot length ratio (SL/RL) in alfalfa Medicago sativa $\mathrm{L}$. with no salinity stress (1) and under salinity stress $(0.6 \% \mathrm{NaCl})(2)$ when inoculated with various Sinorhizobium meliloti strains: a - CNI (non inoculated control), b - SHM1-188, c - 1021, d - CA67 (microvegetative trial).

Root length increased by $79 \%$ which could be due to preferential root meristem 1021 inoculation increased shoot weight and length by 56-96\%, and root length reduced significantly (by 21-28\%). At the same time, drastic changes in alfalfa habitus were observed: the root length/shoot length ratio increased by 2-3 times versus non inoculated control (Fig.).

Salinity stress $(0.6 \% \mathrm{NaCl})$ resulted in a SE loss in $\mathrm{S}$ strain CA67: the shoot weight was unchanged compared to control, while their length increased significantly (by $36 \%$ ) (see Table 1).

R strain SHM1-188 and 
stimulation by bacteria. SE in $\mathrm{R}$ strains under salinity stress was higher versus no salinity stress: shoot weight increased by $138-160 \%$ versus control, but their length reduced significantly (for strain SHM1-188) or remained the same (for strain 1021). At the same time, there was a not significant (6-7\%) reduction in root length, so plant habitus was slightly changed (see Fig.).

Since shoot and root length increased under stress only when alfalfa was inoculated with S strain CA67, it is reasonable to assume that the optimal conditions for the growth-stimulating effects of bacteria on plants are created in the very $\mathrm{SE}$ inhibition. However, the effects of low efficiency $\left(\mathrm{Eff}^{+/-}\right)$mutant $\mathrm{F}$, despite its increased salinity tolerance, on plant habitus appeared the same as for the parental strain CF67 (Table 2).

2. Symbiotic efficacy of mutant (F) and parental (CA67) Sinorhizobium meliloti strains in alfalfa Medicago sativa L. depending on the exposure to salinity stress (microvegetative trials)

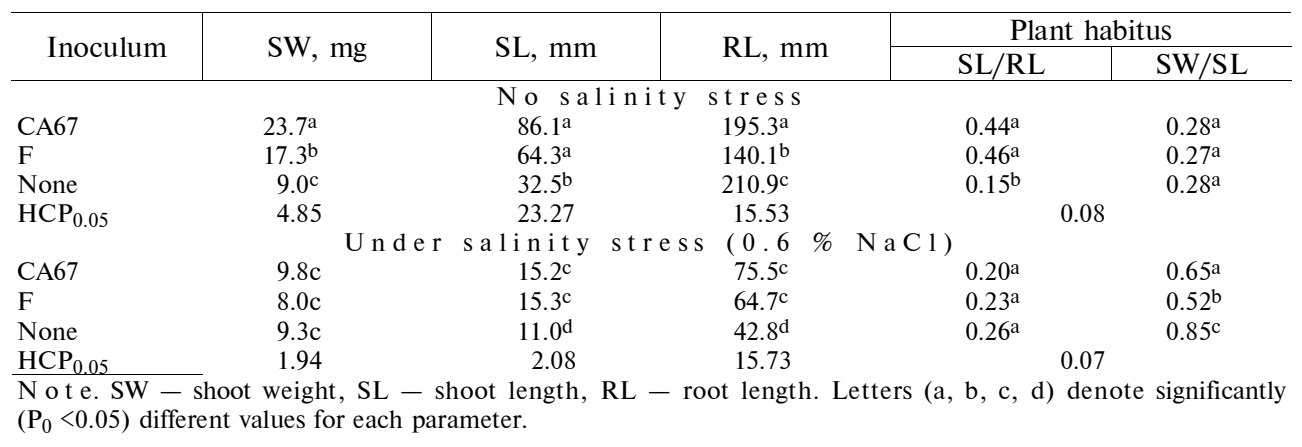

There were no changes in plant habitus for $\mathrm{Eff}^{+/-}$mutant strain GL1 which is not different from parental strain 1021 in salinity tolerance (Table 3).

3. Symbiotic efficacy of mutant (GL1) and parental (1021) Sinorhizobium meliloti strains in alfalfa Medicago sativa L. depending on the exposure to salinity stress (microvegetative trial)

\begin{tabular}{|c|c|c|c|c|c|c|c|}
\hline \multirow{2}{*}{ Inoculum } & \multirow{2}{*}{$\mathrm{SW}, \mathrm{mg}$} & \multirow{2}{*}{$\mathrm{RW}, \mathrm{mg}$} & \multirow{2}{*}{$\mathrm{SL}, \mathrm{mm}$} & \multirow{2}{*}{$\mathrm{RL}, \mathrm{mm}$} & \multicolumn{3}{|c|}{ Plant habitus } \\
\hline & & & & & SW/RW & $\mathrm{SL} / \mathrm{RL}$ & $\mathrm{SW} / \mathrm{SL}$ \\
\hline & & & \multicolumn{5}{|c|}{ No salinity stress } \\
\hline 1021 & $17.9^{\mathrm{a}}$ & $4.3^{\mathrm{a}}$ & $53.1^{\mathrm{a}}$ & $129.6^{\mathrm{a}}$ & $4.16^{\mathrm{a}}$ & $0.40^{\mathrm{a}}$ & $0.34^{\mathrm{a}}$ \\
\hline GL1 & $10.5^{\mathrm{b}}$ & $2.4^{\mathrm{b}}$ & $65.6^{\mathrm{a}}$ & $145.5^{\mathrm{a}}$ & $4.38^{\mathrm{a}}$ & $0.45^{\mathrm{a}}$ & $0.16^{\mathrm{b}}$ \\
\hline None & $7.5^{\mathrm{bd}}$ & $6.5^{\mathrm{c}}$ & $27.9^{\mathrm{b}}$ & $181.1^{\mathrm{b}}$ & $1.15^{\mathrm{b}}$ & $0.15^{\mathrm{b}}$ & $0.27^{\mathrm{a}}$ \\
\hline \multicolumn{8}{|c|}{ Under salinity stress $(0.6 \% \mathrm{NaCl})$} \\
\hline 1021 & $10.7 \mathrm{~b}$ & $5.0^{\mathrm{a}}$ & $20.7 \mathrm{~b}$ & $145.2^{\mathrm{a}}$ & $2.14 \mathrm{c}$ & $0.14 \mathrm{~b}$ & $0.52^{\mathrm{c}}$ \\
\hline GL1 & $10.4 \mathrm{~b}$ & $5.3^{\mathrm{a}}$ & $15.2^{\mathrm{c}}$ & $151.8^{\mathrm{a}}$ & $1.96^{\mathrm{c}}$ & $0.10^{\mathrm{b}}$ & $0.68^{\mathrm{d}}$ \\
\hline None & $4.5^{\mathrm{cd}}$ & $7.3^{\mathrm{c}}$ & $20.8^{\mathrm{b}}$ & $156.0^{\mathrm{a}}$ & $0.61^{b}$ & $0.13^{b}$ & $0.22^{\mathrm{ab}}$ \\
\hline $\mathrm{LSD}_{0.05}$ & 4.23 & 1.27 & 5.11 & 32.54 & 0.97 & \multicolumn{2}{|c|}{0.08} \\
\hline $\begin{array}{l}\text { o t e. SW } \\
\text { gnificantly }\end{array}$ & $\begin{array}{l}\text { t weight } \\
05 \text { ) diffe }\end{array}$ & - roo & ght, SL - & oot length, I & root le & tter & $c$, d) denot \\
\hline
\end{tabular}

The effects of rhizobia inoculation on alfalfa habitus (shoot length/root length ratio) was manifested in the absence of salinity stress only. No significant changes were observed in this parameter, while the shoot weight/shoot length ratio increased from $0.16-0.34 \mathrm{mg} / \mathrm{mm}$ to $0.52-0.68 \mathrm{mg} / \mathrm{mm}$ (see Tables 2 and 3). We have observed a similar change in habitus earlier, when diploid alfalfa $M$. truncatula inoculated with rhizobia were exposed to salinity stress [18]. Since the number of nodules does not change significantly under salinity stress, it is evident that sprout meristem activity in both alfalfa species is inhibited to a greater extent than the activity of nodule meristems [18].

It is reasonable to assume that the increase in shoot length combined with root shortening, which we have seen with alfalfa inoculation with rhizobia in the absence of stress, improves the absorption of fixed nitrogen contributing 
to its translocation into the aerial organs and using for the development of the vegetative mass and seeds. Shoot lengthening and root shortening could be due to the previously detected production of auxin synthesis inhibitors by rhizobia [16] which caused a decrease in the auxins/cytokinins ratio thus stimulating the development of shoot and nodule meristems (similar with shoots in tissue structure) but inhibiting the activity of root meristem. Indeed, cytokinin synthesis intensity in soybean rhizobia (Bradyrhizobium japonicum) correlates with the number of nodules formed and SE [23]. The observed increase in root and shoot lengths in $M$. sativa with S-SA67 strain inoculation under stress could be caused by nitrogenase activity suppression followed by increased phytohormone synthesis which is performed either by bacteria or by plant cells exposed to bacterial signals $[16,25]$.

The effects which we have described may have been due to systemic regulation of nodule formation which starts in model legume Lotus japonicus L. with the induction of bacterial synthesis of signal CLE peptides in the roots [16]. The effects of CLE-peptides on receptor kinase HAR1 synthesized in the shoots caused production of response signals that moved into the roots and blocked formation of excess nodules. At the same time, cytokinin synthesis (LjIPT3 protein controlled) was activated in aerial plant parts, which increased sprout meristem activity, but reduced root meristem activity [24].

Habitus modifications in $M$. sativa observed with the combination of salinity stress and inoculation with salinity-sensitive $S$. meliloti strain SA67 could be due to different changes in hormonal status caused by these effects in aerial and underground organs. Violations of phytohormone synthesis detected in soybean [26] and a number of non-legume plants [27] under salinity stress are known to be complex: they include changes in the levels of salicylic and jasmonic acids involved in the plant response to inoculation with phytopathogenic and symbiotic microorganisms. These changes may reflect the evolutionary association of rhizobia with rhizosphere and endophytic symbionts, the growth-stimulating activity of which is mainly due to the synthesis of phytohormones [28, 29].

Thus, the analysis of plant habitus changes in alfalfa Medicago sativa under inoculation with rhizobia Sinorhizobium meliloti strains and at salinity stress demonstrated that the efficacy of legume-rhizobium symbiosis depends not only on the intensity of $\mathrm{N}_{2}$ fixation, but also on the regulatory effects of microsymbionts that determine hormonal status of host plants. It is reasonable to assume that regulatory effects of rhizobia on legumes in the nodule symbiosis system activate their symbiotrophic development considerably (for example, improving assimilation of $\mathrm{N}_{2}$ fixation products by actively growing aerial organs). Genes controlling these effects can be used to construct rhizobia strains with improved symbiotic efficacy which is defined by the activity of fixed nitrogen assimilation by legumes, and by their tolerance to edaphic stress.

\section{REFEREN CES}

1. Dorosinski i L.M. Kluben'kovye bakterii $i$ nitragin [Nodule bacteria and nitragin]. Leningrad, 1970 (in Russ.).

2. Mishustin E.N., Shil'nikova V.K. Kluben'kovye bakterii i inokulyatsionnyi protsess [Nodule bacteria and inoculation]. Moscow, 1973 (in Russ.).

3. Terpolilli J.J., Hood G.A., P o ole P.S. What determines the efficiency of $\mathrm{N}_{2}$-fixing Rhizobium-legume symbioses? Adv. Microb. Physiol., 2012, 60: 325-389 (doi: 10.1016/B978-012-398264-3.00005-X).

4. Hage A.F., Arnold M.F., Myka K.K., Kerscher B., Dal1'Angelo S., Zanda M., Merga ert P., Fergus on G.P. Molecular insights into bacteroid development 
during Rhizobium-legume symbiosis. FEMS Microbiol. Rev., 2013, 37(3): 364-383 (doi: 10.1111/1574-6976.12003).

5. Sharypova L.A., O nishchuk O.P., Chesnokova O.N., Fomina-Eshenk o J.G., S i m a rov B.V. Isolation and characterization of Rhizobium meliloti Tn5 mutants showing enhanced symbiotic effectiveness. Microbiology, 1994, 140: 463-470.

6. Provorov N.A., O nishchuk O.P., Yurge l' S.N., Kurchak O.N., Chizhevskaya E.P., Vorob'ev N.I., Z a tovskaya T.V., S i marov B.V. Genetika, 2014, 50(11): 1273-1285 (doi: 10.7868/S0016675814110113) (in Russ.).

7. Z a tovskay a T.V. Poluchenie $i$ analiz Tn5-mutantov Sinorhizobium meliloti s izmenennymi poverkhnostnymi polisakharidami. Avtoreferat kandidatskoi dissertatsii [Obtaining and analysis of surface polysaccharide Tn5-mutants in Sinorhizobium meliloti. PhD Thesis]. St. Petersburg, 2012 (in Russ.).

8. Phillips D.A., J o s e ph C.M., Yang G.P., Martine z-Romero E., S a n born J.R., Volpin H. Identification of lumichrome as a Sinorhizobium enhancer of alfalfa root respiration and shoot growth. PNAS USA, 1999, 96(22): 12275-12280 (doi: 10.1073/pnas.96.22.12275).

9. Gouws L.M., Botes E., Wi ese A.J., Trenkamp S., Torres-Jerez I., Tang Y., Hills P.N., Usadel B., Lloyd J.R., Fernie A.R., Kossmann J., van der Me rwe M. The plant growth promoting substance, lumichrome, mimics starch, and ethyleneassociated symbiotic responses in lotus and tomato roots. Front. Plant Sci., 2012 (doi: 10.3389/fpls.2012.00120).

10. Khan W., Prithiviraj B., S mith D.L. Nod factor [Nod Bj V ( $\mathrm{C}_{18: 1}$, MeFuc)] and lumichrome enhance photosynthesis and growth of corn and soybean. J. Plant Physiol., 2008, 165: 1342-1351 (doi: 10.1016/j.jplph.2007.11.001).

11. Philli ps D.A., To r r y J.G. Studies on cytokinin production by Rhizobium. Plant Physiol., 1972, 49(1): 11-15 (doi: 10.1104/pp.49.1.11).

12. Pa la ci os O.A., B a s han Y., d e - B a s han L.E. Proven and potential involvement of vitamins in interactions of plants with plant growth-promoting bacteria - an overview. Biol. Fertil. Soils, 2014, 50: 415-432 (doi: 10.1007/s00374-013-0894-3).

13. Ka nu S.A., M a t i u Y.N., D a k o r a F.D. Strain and species differences in rhizobial secretion of lumichrome and riboflavin, measured using thin-layer chromatography. Symbiosis, 2007, 43: 37-43.

14. Sierra S., Rodelas B., Martinez-Toledo M.V., Pozo C., Gonzalez-Lop e J. Production of B-group vitamins by two Rhizobium strains in chemically-defined media. $J$. Appl. Microbiol., 1999, 86: 851-858 (doi: 10.1046/j.1365-2672.1999.00765.x).

15. S t re it W.R., J o s e p h C.M., Philli ps D.A. Biotin and other water-soluble vitamins are key growth factors for alfalfa root colonization by Rhizobium meliloti 1021. Mol. Plant-Microbe Interact., 1996, 5: 330-338.

16. Fergus on B., Mathesius U. Phytohormone regulation of legume-rhizobia interactions. J. Chem. Ecol., 2014, 40: 770-790 (doi: 10.1007/s10886-014-0472-7).

17. Ogutcu H., Kasi mogly C., Elk o a E. Effect of Rhizobium strains isolated from wild chickpeas on the growth and symbiotic performance of chickpeas (Cicer arietinum L.) under salt stress. Turkish J. Agric. Res., 2010, 34: 361-371 (doi: 10.3960/tar-0940-34).

18. Kurchak O.N., Provorov N.A., Onishchuk O.P., Vorob'ev N.I., Rumyantseva M.L., Simarov B.V. Genetika, 2014, 50(7): 777-786 (doi: 10.7868/S001667581406006X) (in Russ.).

19. Meade H.M., Long S.R., Ruvkun G.B., B rown S.E., Ausubel F.M. Physical and genetic characterization of symbiotic and auxotrophic mutants of Rhizobium meliloti induced by transposon Tn5 mutagenesis. J. Bacteriol., 1982, 149: 114-122.

20. Fedorov S.N., S i ma rov B.V. Sel'skokhozyaistvennaya Biologiya [Agricultural Biology], 1987, 9: 44-49 (in Russ.).

21. Roumiantseva M.L., Andronov E.E., Sharypova L.A., D a m ma n-Kali nov s k i T., K e lle r M., Y o u ng J.P.W., S i m a rov B.V. Diversity of Sinorhizobium meliloti from the Central Asian alfalfa gene center. Appl. Environ. Microbiol., 2002, 68(9): 4694-4697 (doi: 10.1128/AEM.68.9.4694-4697.200).

22. L a k i n G.F. Biometriya [Biometry]. Moscow, 1980 (in Russ.).

23. D ragovoz I.V., Le o nova N.O., I u t i nsk y a G.A. Mikrobiologicheskii zhurnal, 2011, 3: 29-35 (in Russ.).

24. Okamoto S., Ohnishi E., S ato S., Takahashi H., Nakazono M., Taba t a S., K a w a g u c h i M. Nod factor/nitrate-induced $C L E$ genes that drive HAR1-mediated systemic regulation of nodulation. Plant Cell Physiol., 2009, 50: 67-77 (doi: 10.1093/pcp/pcn194).

25. Theunis M., Kobayashi H., Broughton W., Prinsen E. Flavonoids, NodD1, NodD2, and nod-box NB15 modulate expression of the y4wEFG locus that is required for indole-3-acetic acid synthesis in Rhizobium sp. strain NGR234. Mol. Plant-Microbe Interact., 2004, 17(10): 1153-1161 (doi: 10.1094/MPMI.2004.17.10.1153).

26. Ha mayun M., Khan S.A., Khan A.L., Shinwari Z.K., Hus sai n J., Song E.Y., 
K a ng S.M., Ki m Y.H., K ha n M.A., L e e I.J. Effect of salt stress on growth attributes and endogenous growth hormones of soybean cultivar Hwangkeumkong. Pakist. J. Bot., 2010, 42(5): 3103-3112.

27. Ry u H., C ho Y.G. Plant hormones and salt stress tolerance. J. Plant Biol., 2015, 58: 147-155 (doi: 10.1007/s12374-015-0103-z).

28. Provo rov N.A., V o r o b'e v N.I. Geneticheskie osnovy evolyutsii rastitel'no-mikrobnogo simbioza /Pod redaktsiei I.A. Tikhonovicha [Evolution of plant-microbe symbiosis - a genetic basis. I.A. Tikhonovich (ed.)]. St. Petersburg, 2012 (in Russ.).

29. Yang J., Kloepper J.W., Ry u C.M. Rhizosphere bacteria help plants tolerate abiotic stress. Trends in Plant Sci., 2009, 14(1): 1-4. 